\title{
News from statistical offices
}

\section{Ireland}

\section{Technology transfer}

The Irish Central Statistics Office (CSO) was obliged to replace its Business Register computer system. After studying several options and reviewing available documentation, it was decided that the new Business Frame (BF) system developed by Statistics New Zealand (SNZ) seemed to be the most suitable for the Irish CSO requirements. Experts from both offices carried out an evaluation of the SNZ BF system in August 1997 which proved that the general design, statistical unit models and powerful functionality of the system was ideal and the first prototype was constructed.

This technology transfer project was a resounding success and is an excellent example of cooperation between national statistical services from opposite sides of the world.

For further information contact: Ray Freeman, Statistics New Zealand, Private Bag 92003, Auckland, New Zealand. Tel.: +64-9 357-2100; Fax: +64-9 359-0859; E-mail: Ray_Freeman \%STATISTICS_NZ@ stats.govt.nz. Tom Keane, Central Statistics Office, Skehard Road, Cork, Ireland. Tel.:
+353-21 359-000; Fax: +353-21 359159; E-mail: KeaneT@cso.ie.

\section{Norway}

\section{Joint cooperation}

For some time now, Norway has been supporting the collection and analysis of statistical data in Palestinian areas starting with a Living Conditions Survey which contributed to the Oslo Agreement between the Palestinians and the Israelis. It is now offering grants to the Palestinian Central Bureau of Statistics. Support was given for the first Palestinian population census which took place last December which has provided important data for the creation of such registers as: a population register, housing and dwellings register, register of establishments, and an agriculture holders register. The rather sensitive political situation in the area, of course, poses many challenges to the development of statistical routines and conducting surveys and censuses. Statistics Norway needs experienced statistical advisers to send to Palestine for short-term or long-term missions. If you are interested in joining the team please contact Jan Lyngstad, tel.: +9722 998-6340, ext. 216; or Bjoern Wold, Tel.: +47-22 86.46.60. 


\section{Turkey}

\section{Publication}

In 1998 the Turkish Statistical Association began publishing three times a year ISTATISTIK which is a bilingual (English and Turkish) scientific journal in statistics. The main areas covered in this publication are probability and stochastic processes, statistical theory, applied statistics, optimization, statistical computing and simulation, and interdisciplinary applications in social, demographic, engineering, physical, biolog- ical, agricultural, computer science, management science and econometrics. In addition, the Journal contains original research reports, authoritative review papers, discusses papers and occasional special issues on particular topics or on relevant conference proceedings.

Contributions should be sent to the editor: Prof. De. Ömer L. Gebizlioglu, Ankara University, Faculty of Science, Department of Statistics, 06100 Tandogan, Ankara, Turkey. Fax: +90 312 2232395; E-mail: gebizli@science.ankara.edu.tr. 